\title{
Excess mechanical stress and hydrogen peroxide remodel extracellular matrix of cultured human uterosacral ligament fibroblasts by disturbing the balance of MMPs/TIMPs via the regulation of TGF- $\beta 1$ signaling pathway
}

\author{
QIFAN ZHANG, CHENG LIU, SHASHA HONG, JIE MIN, QING YANG, MING HU, YANG ZHAO and LI HONG
}

Department of Obstetrics and Gynecology, Renmin Hospital of Wuhan University, Wuhan, Hubei 430060, P.R. China

Received October 16, 2015; Accepted October 31, 2016

DOI: $10.3892 / \mathrm{mmr} .2016 .5994$

\begin{abstract}
The regulation of the extracellular matrix (ECM) by mechanical stress is of interest as the ECM is essential in the development of pelvic organ prolapse. In the present study, the effect of overexposure to mechanical stress on the ECM, and the probable underlying mechanisms in cultured human uterosacral ligament fibroblasts (hUSLFs), was explored. Mechanical stress has an effect on oxidation-antioxidation products in parametrial ligament fibroblasts. Thus, hUSLFs were incubated with different concentrations of hydrogen peroxide to elucidate any potential interactions. Excess mechanical stress and $\mathrm{H}_{2} \mathrm{O}_{2}$ inhibited cell proliferation, and decreased mRNA and protein expression levels of ECM components, collagen 1, collagen 3 and elastin. Further analysis revealed that the mRNA expression level of matrix metalloproteinase-2 (MMP-2) was increased and TIMP metallopeptidase inhibitor 2 (TIMP-2) decreased, and in addition the MMP2/TIMP2 mRNA ratio was increased, which may facilitate the degradation of the ECM. Due to the key role of the transforming growth factor $\beta 1$ (TGF- $\beta 1) /$ mothers against decapentaplegic homolog $2(\operatorname{Smad} 2)$ signaling pathway in fibrosis, the present study investigated the effect of excess mechanical stress and $\mathrm{H}_{2} \mathrm{O}_{2}$ on TGF- $\beta 1 / \mathrm{Smad} 2$ signaling. The results indicated that excess mechanical stress and $\mathrm{H}_{2} \mathrm{O}_{2}$ treatment suppressed phosphorylated Smad2 expression and decreased the levels of TGF- $\beta 1$. Activation of the TGF- $\beta 1$ signaling pathway by either mechanical stress or $\mathrm{H}_{2} \mathrm{O}_{2}$ was demonstrated to attenuate cell proliferation and ECM components, and also increased the MMP2/TIMP2 mRNA ratio. These findings suggested that mechanical stress and $\mathrm{H}_{2} \mathrm{O}_{2}$
\end{abstract}

Correspondence to: Dr Li Hong, Department of Obstetrics and Gynecology, Renmin Hospital of Wuhan University, 9 Zhang Zhi Dong Street, Wuchang, Wuhan, Hubei 430060, P.R. China E-mail: drhongli77@gmail.com

Key words: mechanical stress, hydrogen peroxide, extracellular matrix, TGF- $\beta 1$ signaling pathway, pelvic organ prolapsed overexposure inhibit cell proliferation and remodel the ECM network via regulation of the TGF- $\beta 1$ signaling pathway.

\section{Introduction}

Mechanical stress is important for functional development and maintenance of animal tissues. In various cases, organs and tissues adapt their morphology and function in response to acute or chronic mechanical stress, for example, pressure overload leads to cardiovascular hypertrophy (1) and excess mechanical stress may alter cartilaginous composition and metabolism, resulting in osteoarthritis (2). Certain epidemiological investigations have demonstrated that long-lasting mechanical stress due to a history of vaginal delivery, pregnancy and high abdominal pressure may be the most common risk factor of pelvic organ prolapse (POP) $(3,4)$. Oxidative stress is a harmful imbalance between the production and the removal of free radicals, including reactive oxygen species (ROS) and lipid peroxidation end products (5). Currently, there appears to be evidence that the occurrence of POP may be associated with the imbalance of the oxidation-reduction equilibrium in vivo $(6,7)$ and remodeling of the extracellular matrix (ECM), but this has not been not clearly demonstrated. When fibroblasts react to changes in mechanical stress, components of the ECM are also altered, particularly when a certain degree of force is reached, which may induce oxidative damage and subsequently activate the antioxidation system (8).

Transforming growth factor- $\beta 1$ (TGF- $\beta 1$ ) has been reported to be a profibrogenic cytokine that contributes to multiple forms of fibrosis, including cardiac fibrosis associated with heart failure $(9,10)$. Certain evidence suggests that mechanical stress may induce the release of TGF- $\beta 1$ (11). TGF- $\beta 1$ may alter the balance between ECM synthesis and degradation in numerous processes, including tissue injury (12) and pulmonary fibrosis (13). Previous studies have demonstrated that remodeling of connective tissues may contribute to the pathogenesis of POP $(14,15)$.

The present study hypothesized that the TGF- $\beta 1$ pathway, along with oxidative stress, is associated with remodeling of the ECM induced by mechanical stretch. Human uterosacral ligament fibroblasts (hUSLFs) treated with mechanical stress and hydrogen peroxide were cultured in order to elucidate 
the association between mechanical stress and the TGF- $\beta 1$ signaling pathway and to define the role of oxidative stress in the remodeling of the ECM.

\section{Materials and methods}

Ethics statement. Human samples used in the present study were obtained according to the principles expressed in the Declaration of Helsinki, and were approved by the Institutional Review Boards of the Renmin Hospital of Wuhan University (Wuhan, China). Written informed consent was obtained from the patients.

Clinical specimens. A cohort of 15 patients who had undergone a total vaginal hysterectomy due to benign uterine disease at Renmin Hospital of Wuhan University had samples of the uterosacral ligament tissues collected. Inclusion criteria were as follows: i) Patients who had not taken any oral estrogen for at least 3 months; ii) patients who were not suffering from estrogen-responsive diseases, including endometriosis; and iii) patients without diabetes and cardiovascular disease.

Cell culture. A modified enzyme digestion method was used to obtain hUSLFs. The tissues $(0.5 \times 0.5 \times 0.2 \mathrm{~cm})$ were placed into Dulbecco's modified Eagle's medium (DMEM; Genom Hangzhou, China) immediately following separation during surgery, and were then taken to the laboratory for exposure to a $4^{\circ} \mathrm{C}$ environment within $30 \mathrm{~min}$. The tissues were washed with phosphate-buffered saline (PBS; Genom) containing $100 \mathrm{U} / \mathrm{ml}$ penicillin $\mathrm{G}$ and $100 \mathrm{mg} / \mathrm{ml}$ streptomycin (Genom), and were then cut into small pieces. The tissues were then digested with $1 \%$ collagenase I (Invitrogen; Thermo Fisher Scientific, Inc., Waltham, MA, USA) for $3 \mathrm{~h}$ at $37^{\circ} \mathrm{C}$ in $5 \%$ $\mathrm{CO}_{2}$, followed by further digestion with $0.25 \%$ trypsin (Sigma-Aldrich; Merck Millipore, Darmstadt, Germany) for 5 min. Fetal bovine serum (FBS; Hyclone, GE Healthcare, Logan, UT, USA) was used to terminate the digestion. DMEM containing $15 \%$ FBS was then slowly added to the culture flask. The medium was replaced every two days and the primary hUSLFs cultures were grown to confluence for passage. Fibroblasts at passage 2-3 were used.

Mechanical stress. The fibroblasts were loaded with mechanical stress by a four-point bending device (Chengdu Miracle Chemicals Co., Ltd., Chengdu, China) composed of three sections, including a mechanical system, main engine and strain loading plate. A cell suspension containing fibroblasts was produced with DMEM containing 10\% FBS, following digestion by trypsin and EDTA (Sigma-Aldrich; Merck Millipore). Cell suspension ( $2 \mathrm{ml}$ ) was added onto a plate that had been preprocessed using rat tail collagen and placed into an $11 \mathrm{~mm}$ culture dish, which was incubated at a temperature of $37^{\circ} \mathrm{C}$ with $5 \% \mathrm{CO}_{2}$ for a minimum of $24 \mathrm{~h}$. Following cell adherence and subconfluence, the cell plate was put into the strain loading plate under a loading strain of $0,1,333(1 \mathrm{~mm})$ or $5,333 \mu(4 \mathrm{~mm})$ at a frequency of $0.1 \mathrm{~Hz}$, for $4 \mathrm{~h}$.

Hydrogen peroxide treatment. Fibroblasts at passage 4-6 were manipulated to cell suspension with DMEM containing $10 \%$ FBS, following digestion by trypsin. Cells were plated in 6-well plates and grown overnight at $37^{\circ} \mathrm{C}$ to $80-90 \%$ confluence. Fibroblasts were incubated with $\mathrm{H}_{2} \mathrm{O}_{2}$ at a concentration of $0,0.2,0.4$ and $0.8 \mathrm{mmol} / 1$ for $4 \mathrm{~h}$ at $37^{\circ} \mathrm{C}$ under $5 \% \mathrm{CO}_{2}$.

Cell proliferation detection. Following exposure to mechanical strain and hydrogen peroxide, a Cell Counting Kit-8 (CCK-8; Beyotime Institute of Biotechnology, Shanghai, China) was used to count the cells and detect their magnitude of proliferation. Coverslips and culture plates were then washed three times with PBS. The cells then underwent digestion with $0.25 \%$ trypsin and EDTA, followed by the addition of DMEM containing $15 \%$ FBS to the cell precipitation. The cells were subsequently centrifuged at $125 \mathrm{x} \mathrm{g}$ for $5 \mathrm{~min}$ at $37^{\circ} \mathrm{C}$. Cell concentration was adjusted to 2 million $/ \mathrm{ml}$ and $100 \mu \mathrm{l}$ cell suspension was added to a 96-well plate. After 12-24 h of incubation, CCK-8 solution (10 $\mu \mathrm{l} /$ well) was added to each well and incubated for $2 \mathrm{~h}$. The optical density at a wavelength of $450 \mathrm{~nm}$ was detected using an enzyme-labeled instrument.

Detection of intracellular ROS. Cellular ROS production was determined fluorometrically using dichlorofluorescein (DCF) diacetate as a fluorescent probe. Following administration of specific treatments, the cells were incubated with the probe for $60 \mathrm{~min}$ at $37^{\circ} \mathrm{C}$ in the dark, and they were then washed and resuspended in phosphate-buffered saline. The fluorescence emitted at a wavelength of $488 \mathrm{~nm}$ was measured with a fluorescence microscope. The values were expressed as a percentage of the fluorescence measured in the control, and ROS levels were expressed as a percentage of that in the control.

Reverse transcription-quantitative polymerase chain reaction (RT-qPCR). Total RNA was isolated from cells following treatment, using TRIzol reagent (Invitrogen; Thermo Fisher Scientific, Inc.) according to the manufacturer's protocols. For mRNA analysis, cDNA was amplified from $2.0 \mu \mathrm{g}$ total RNA in a final volume of $20 \mu \mathrm{l}$ using Revert Aid $^{\mathrm{TM}}$ First Strand cDNA Synthesis kit (Fermentas; Thermo Fisher Scientific, Inc.). Human GAPDH was amplified as an internal control. The RT-qPCR reaction was performed using Takara SYBR Premix ExTaq system (Takara Bio, Inc., Otsu, Japan). qPCR was performed as follows: $30 \mathrm{sec}$ at $95^{\circ} \mathrm{C} ; 40$ cycles of $5 \mathrm{sec}$ at $95^{\circ} \mathrm{C}$, and $34 \mathrm{sec}$ at $60^{\circ} \mathrm{C} ; 15 \mathrm{sec}$ at $95^{\circ} \mathrm{C}, 1 \mathrm{~min}$ at $60^{\circ} \mathrm{C}, 15 \mathrm{sec}$ at $95^{\circ} \mathrm{C}$ and $15 \mathrm{sec}$ at $60^{\circ} \mathrm{C}$. The ABI 7500 Fast Real-Time PCR system (Applied Biosystems; Thermo Fisher Scientific, Inc.) was used. The data was processed using $2^{-\Delta \Delta \mathrm{Cq}}$ method relative to GAPDH (16). Primer sequence information is listed in Table I.

Western blot analysis. Following washing in cold PBS, the harvested cells were lysed on ice for $30 \mathrm{~min}$ in $100 \mathrm{mmol} / \mathrm{l}$ lysis buffer. Extracts were centrifuged at $16,099 \times \mathrm{g}$ at $37^{\circ} \mathrm{C}$ for $15 \mathrm{~min}$. The supernatant was collected as the total cellular protein extract. The protein concentrations were determined using a bicinchoninic acid protein assay kit. For western blot analysis, equal quantities of protein (35 $\mu \mathrm{g})$ were run in each lane on a Tris-glycine gel using 10\% SDS-PAGE. Following electrophoresis, the proteins were transferred to a polyvinylidene difluoride membrane and then the membranes 
Table I. Primer sequences used for polymerase chain reaction.

\begin{tabular}{ll}
\hline Gene & \multicolumn{1}{c}{ Sequence (5'-3') } \\
\hline COL1A1 & F: CAAGACGAAGACATCCCACCAATC \\
& R: ACAGATCACGTCATCGCACAACA \\
COL3A1 & F: TCGCTCTGCTTCATCCCACTAT \\
& R: CTTCCAGACATCTCTATCCGCAT \\
Elastin & F: TGTCCATCCTCCACCCCTCT \\
& R: CGGTCGTAGTCCTCAGTGGT \\
MMP-2 & F: AGTTTCCATTCCGCTTCCAG \\
& R: CGGTCGTAGTCCTCAGTGGT \\
TIMP-2 & F: TCTGGAAACGACATTTATGG \\
& R: GTTGGAGGCCTGCTTATGGG \\
TGF- 31 & F: TATTGAGCACCTTGGGCACT \\
& R: ACCTCTCTGGGCTTGTTCC \\
GAPDH & F: GAAGGTGAAGGTCGGAGTC \\
& R: GAAGATGGTGATGGGATTTC
\end{tabular}

COL1A1, collagen type $1 \alpha 1$ chain; COL3A1, collagen type $3 \alpha 1$ chain; MMP-2, matrix metalloproteinase-2; TIMP-2, TIMP metallopeptidase inhibitor 2 ; TGF- $\beta 1$, transforming growth factor $\beta 1$; $\mathrm{F}$, forward; R, reverse.

were probed with the following primary antibodies overnight at $4^{\circ} \mathrm{C}$ : Anti-collagen, type $1 \alpha 1$ chain (COL1A1; 1:400; cat. no. sc-8784; Santa Cruz Biotechnology, Inc., Dallas, TX, USA), anti-collagen type $3 \alpha 1$ chain (COL3A1; 1:400; cat. no. sc-28888; Santa Cruz Biotechnology, Inc.), anti-matrix metalloproteinase-2 (MMP-2; 1:400; cat. no. sc-10736; Santa Cruz Biotechnology, Inc.), anti-TIMP metallopeptidase inhibitor 2 (TIMP-2; 1:500; cat. no. sc-5539; Santa Cruz Biotechnology, Inc.), anti-TGF- $\beta 1$ (1:1,000; cat. no. ab92486; Abcam, Cambridge, UK), anti-mothers against decapentaplegic homolog 2 (Smad2; 1:500; cat. no. ab63576; Abcam), anti-phosphorylated (p)-Smad2 (1:300; cat. no. ab53100; Abcam) and anti-GAPDH (1:1,000; cat. no. sc-20357; Santa Cruz Biotechnology, Inc.). Subsequent to washing in TBST, the membrane was incubated with diluted horseradish peroxidase-conjugated secondary antibodies IRDye $800 \mathrm{CW}$ goat anti-rabbit and goat anti-mouse secondary antibodies (diluted 1/10,000, cat. nos. P/N 925-32211 and P/N 925-32210, LI-COR Biosciences, Ltd., Lincoln, NE, USA) at $37^{\circ} \mathrm{C}$ for $1 \mathrm{~h}$. The Odyssey Imaging system (LI-COR Biosciences, Ltd.) was used for quantification of proteins. Experiments were performed three times obtaining similar results.

Statistical analysis. Statistical analyses were performed with SPSS 19.0 software (IBM SPSS, Armonk, NY, USA). Data are presented as the mean \pm standard deviation, and depict the average of at least 3 independent experiments. All experiments were analyzed with independent samples t-test and $95 \%$ confidence interval was used. Dunnett's T3 test was used for the unequal variances. $\mathrm{P}<0.05$ was considered to indicate a statistically significant difference and $\mathrm{P}<0.01$ was considered highly significant.

\section{Results}

Effect of mechanical stress on oxidation-antioxidation balance of hUSLFs. As presented in Fig. 1, using DCF fluorescence labeling, the present study observed an increase in intracellular ROS triggered by mechanical stress. Furthermore, following loading of 5,333 $\mu$ mechanical stress, the manganese superoxide dismutase (MnSOD) protein expression levels in hUSLFs were lower than those of the control group, $(\mathrm{P}<0.01)$ while increased with the strain of $1,333 \mu(\mathrm{P}<0.05)$, suggesting that mechanical stress has an effect on oxidation-antioxidation products in parametrial ligament fibroblasts. hUSLFs were then incubated with different concentrations of hydrogen peroxide in the following experiments to investigate potential associations.

Effect of mechanical stress and hydrogen peroxide on proliferation of hUSLFs. The present study assessed the effect of mechanical stress and $\mathrm{H}_{2} \mathrm{O}_{2}$ on hUSLFs by measuring cell viability with a CCK-8 assay. As presented in Fig. 2, $\mathrm{H}_{2} \mathrm{O}_{2}$ treatment was administered at a range of 0.2 to $0.8 \mathrm{mmol} / \mathrm{l}$. Cell proliferation was significantly inhibited at the high concentration of $0.8 \mathrm{mmol} / \mathrm{l}(\mathrm{P}<0.05)$ and concentrations of $0.2 \mathrm{mmol} / \mathrm{l}$ $(\mathrm{P}<0.01)$ and $0.4 \mathrm{mmol} / \mathrm{l}$ promoted cell proliferation.

Furthermore, the cell viability decreased under the influence of mechanical force. The group with strains of 1,333 and $5,333 \mu$ indicated lower cell viability compared with the control group, $(\mathrm{P}<0.05$ and $\mathrm{P}<0.01$, respectively; Fig. 2$)$ demonstrating that the cell viability gradually decreased with the increase in mechanical force.

Effects of mechanical stress and hydrogen peroxide on protein and $m R N A$ expression levels of ECM components. To determine how mechanical stress and $\mathrm{H}_{2} \mathrm{O}_{2}$ alter the production of individual ECM components, which are known to be key in the pathological process of POP, the present study detected mRNA and protein expression levels of precursor COL1A1, precursor COL3A1 and elastin by RT-qPCR and western blotting, respectively. As presented in Figs. 3 and 4, the results demonstrated that incubation of hUSLFs with $\mathrm{H}_{2} \mathrm{O}_{2}$ resulted in a significant inhibitory effect on the expression of COL1A1, COL3A1 and elastin at the high concentration of $0.8 \mathrm{mmol} / \mathrm{l}$ $(\mathrm{P}<0.01)$, while $\mathrm{H}_{2} \mathrm{O}_{2}$ at a concentration of 0.2 and $0.4 \mathrm{mmol} / \mathrm{l}$ promoted the expression of mRNA and protein. Furthermore, the expression of mRNA and protein levels significantly decreased with high strains of $5,333 \mu,(\mathrm{P}<0.01)$, however, the levels increased with lower strains of $1,333 \mu$.

Effects of mechanical stress and hydrogen peroxide on $m R N A$ expression of matrix MMP-2 and TIMP-2. Incubation of hUSLFs with $\mathrm{H}_{2} \mathrm{O}_{2}$ resulted in significant inhibition of MMP-2 expression in transcription levels at low concentration of $0.2 \mathrm{mmol} / \mathrm{l}(\mathrm{P}<0.05)$. As the activity of MMP-2 is primarily regulated via the antiprotease TIMP-2, the present study then investigated how $\mathrm{H}_{2} \mathrm{O}_{2}$ affects TIMP-2. The results indicated that the expression of TIMP-2 was significantly decreased by $\mathrm{H}_{2} \mathrm{O}_{2}$ at the high concentration of $0.8 \mathrm{mmol} / \mathrm{l}(\mathrm{P}<0.05)$, while MMP-2 levels demonstrated a decrease at $0.2 \mathrm{mmol} / \mathrm{l}$ and an increase at $0.8 \mathrm{mmol} / 1$ as presented in Fig. 5. The ratios of enzyme/inhibitor mRNA expression were calculated, in 
$\mathbf{A}$

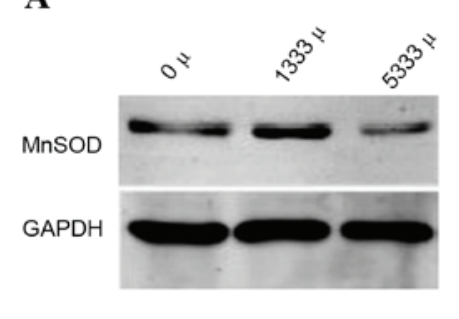

B

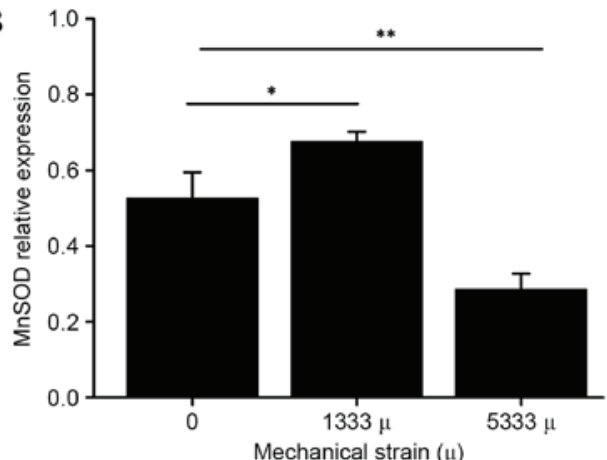

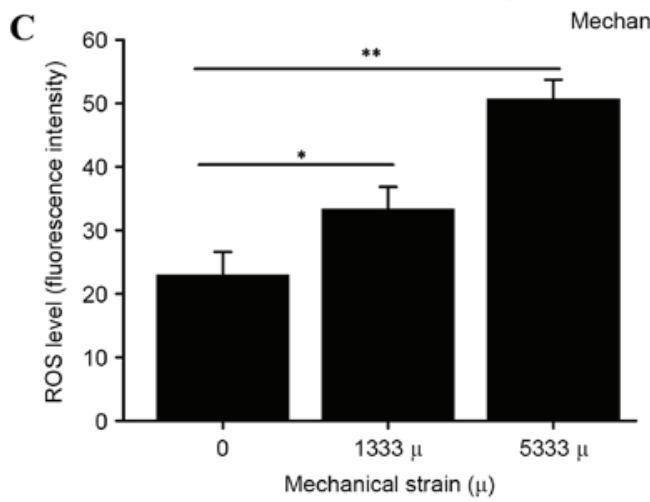

Figure 1. Effect of mechanical stress on the oxidation-antioxidation balance of hUSLFs. (A) Western blot analysis of the levels of MnSOD. GAPDH served as a loading control. (B) Densitometric analysis for the level of MnSOD expression was performed. (C) hUSLFs were loaded with dichlorodihydrofluorescein to monitor ROS generation in the presence of mechanical stress for $4 \mathrm{~h}$. Fluorescence was measured using a fluorescence microscope. Error bars represent the mean \pm standard deviation. ${ }^{*} \mathrm{P}<0.05,{ }^{* * *} \mathrm{P}<0.01$. MnSOD, manganese superoxide dismutase; ROS, reactive oxygen species; hUSLFs, human uterosacral ligament fibroblasts.
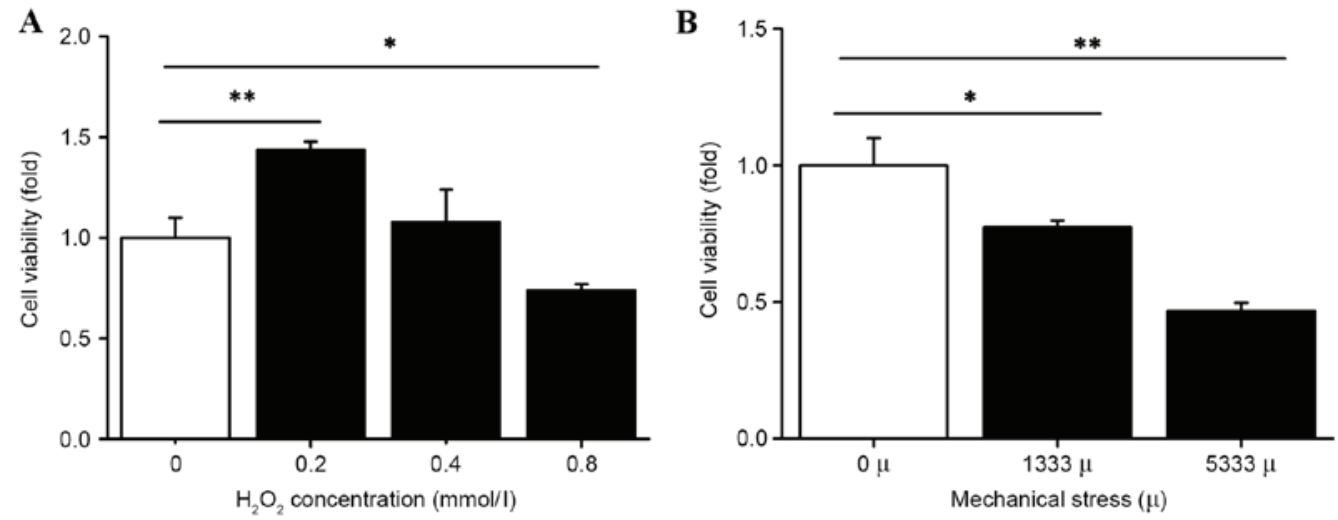

Figure 2. Effect of mechanical stress and hydrogen peroxide on proliferation of hUSLFs. hUSLFs were treated with (A) different concentrations of $\mathrm{H}_{2} \mathrm{O}_{2}$ for $4 \mathrm{~h}$ or (B) mechanical stress, and analyzed for cell growth with a Cell Counting Kit-8 assay. The values were normalized to the results in untreated cells. Error bars represent the mean \pm standard deviation. ${ }^{*} \mathrm{P}<0.05,{ }^{* *} \mathrm{P}<0.01$. hUSLFs, human uterosacral ligament fibroblasts.

order to provide a more comprehensive method to analyze the proteolytic balance. In cells treated with $0.8 \mathrm{mmol} / 1 \mathrm{H}_{2} \mathrm{O}_{2}$ a significant increase in the ratio of enzyme/inhibitor mRNA expression levels $(\mathrm{P}<0.01)$ was observed, which may facilitate the degradation of ECM.

In addition, the cells with strain of $1,333 \mu$ demonstrated significantly higher mRNA expression of TIMP-2 $(\mathrm{P}<0.01)$, and lower mRNA expression of MMP-2 compared with the control group $(\mathrm{P}<0.05)$, but a high strain of $5,333 \mu$ indicated an opposite result ( $\mathrm{P}<0.01$ of MMP-2/TIMP-2.

Effect of excess mechanical stress and hydrogen peroxide on the TGF- $\beta 1 /$ Smad 2 pathway. TGF- $\beta 1$ initiates cellular activity by binding to and activating TGF- $\beta$ receptor II (TR $\beta$ II) and is mediated by Smad transcription factors. In patients with POP, the expression of ECM proteins were decreased, therefore, the present study only selected the mechanical stress level of $5,333 \mu$ and $\mathrm{H}_{2} \mathrm{O}_{2}$ concentration of $0.8 \mathrm{mmol} / 1$ to investigate the activity of the TGF- $\beta 1 / \mathrm{Smad} 2$ signaling pathway. The western blot analysis revealed that expression of TGF- $\beta 1$ was significantly decreased by excess mechanical stress of $5,333 \mu$ and $\mathrm{H}_{2} \mathrm{O}_{2}$ at concentration of $0.8 \mathrm{mmol} / \mathrm{l}$ (Fig. 6; $\mathrm{P}<0.01$ ). The Smad family is the most important mediator for TGF- $\beta 1$ signaling, which resulted in examination of the post-receptor regulation of TGF- $\beta 1$. As presented in Fig. 6, excess mechanical stress and $\mathrm{H}_{2} \mathrm{O}_{2}$ treatment significantly suppressed the 

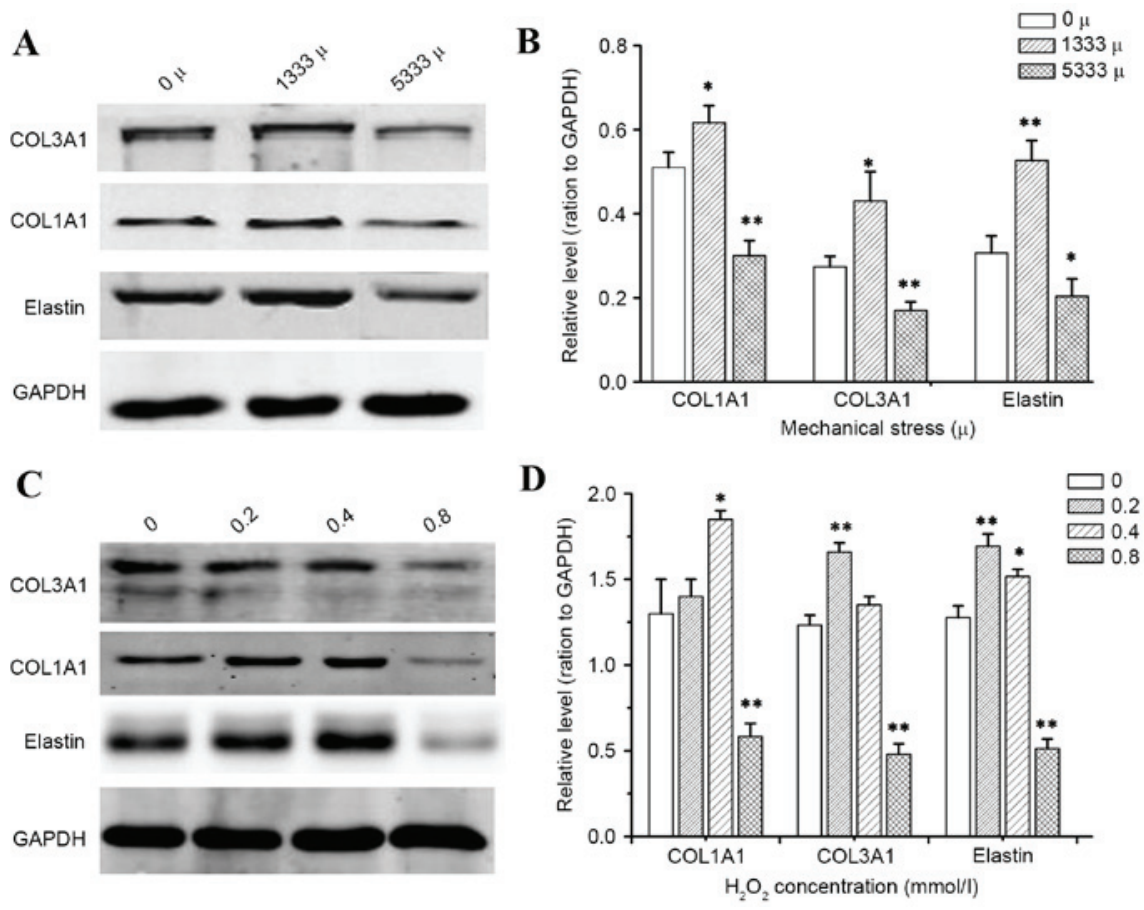

Figure 3. Effects of (A and B) mechanical stress and (C and D) hydrogen peroxide on protein expression of extracellular matrix components of hUSLFs Western blot analysis of the expression levels of COL1A1, COL3A1 and elastin of hUSLFs treatment with (A) mechanical stress, or (C) different concentrations of $\mathrm{H}_{2} \mathrm{O}_{2}$. GAPDH served as a loading control. (B and D) Densitometric analysis for the level of protein expression were performed. Error bars represent the mean \pm standard deviation. ${ }^{*} \mathrm{P}<0.05,{ }^{* *} \mathrm{P}<0.01$ vs. $0 \mu$ (B) or $0 \mathrm{mmol} / \mathrm{l}$ (D). hUSLFs, human uterosacral ligament fibroblasts; COL1A1, collagen type $1 \alpha 1$ chain; COL3A1, collagen type $3 \alpha 1$ chain.
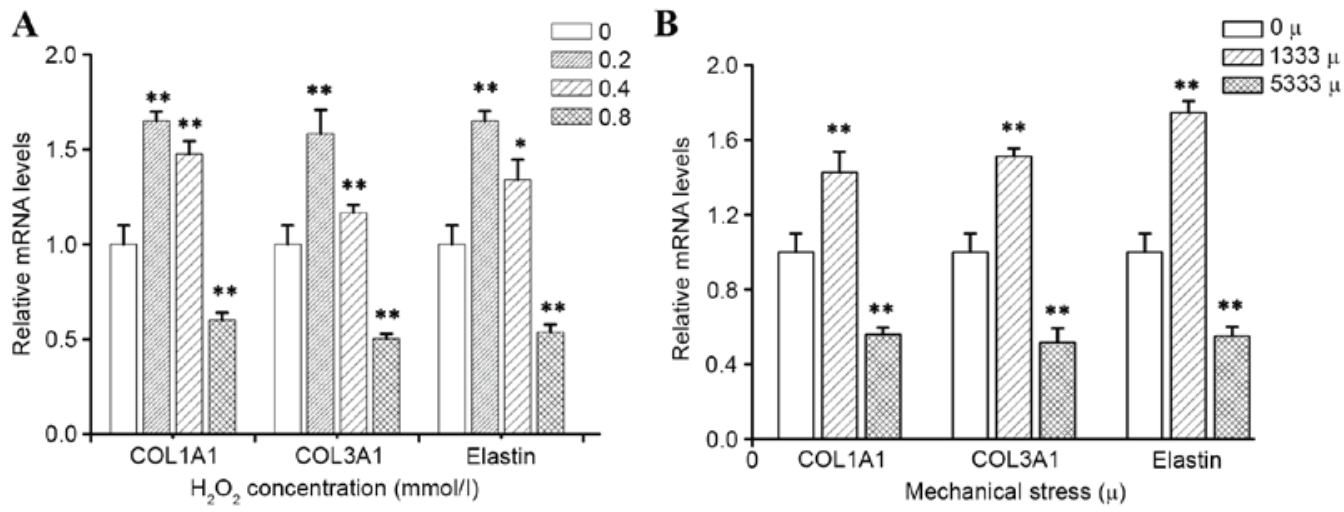

Figure 4. Effects of mechanical stress and hydrogen peroxide on mRNA expression of extracellular matrix components of human uterosacral ligament fibroblasts. The housekeeping gene GAPDH served as an internal control, and mRNA expression was normalized to GAPDH expression using the $2^{-\Delta \Delta C q}$ method following application of (A) hydrogen peroxide and (B) mechanical stress. Error bars represent the mean \pm standard deviation. ${ }^{~} \mathrm{P}<0.05,{ }^{* *} \mathrm{P}<0.01 \mathrm{vs}$. $0 \mathrm{mmol} / 1$ (A) or $0 \mu$ (B). GAPDH, glyceraldehyde 3-phosphate dehydrogenase; COL1A1, collagen type $1 \alpha 1$ chain; COL3 $\alpha 1$, collagen type $3 \alpha 1$ chain.

levels of p-Smad2 $(\mathrm{P}<0.01)$. These results suggest that excess mechanical stress and $\mathrm{H}_{2} \mathrm{O}_{2}$ may lead to the suppression of TGF- $\beta 1 /$ Smad 2 signaling.

\section{Discussion}

Numerous pathophysiological processes in the human body result in cells withstanding varying levels of mechanical stress. Cells that can be affected include cardiac myocytes and fibroblasts (17), vascular endothelial and smooth muscle cells (18), tendon and ligament fibroblasts $(19,20)$ and fibroblasts and myofibroblasts during wound healing. The present study observed an increase in intracellular ROS and abnormal expression of MnSOD, an antioxidant enzyme, triggered by mechanical stress (Fig. 1), demonstrating that mechanical stress has an effect on oxidation-antioxidation products in hUSLFs. Thus, hUSLFs were incubated with different concentrations of $\mathrm{H}_{2} \mathrm{O}_{2}$ in the subsequent experiments to investigate the potential associations.

The activity and proliferation ability of cells is reduced when the cells are subjected to external injury and this acts as an important indicator in measuring cell state (21). The present study provided data to support that excessive mechanical stress and $\mathrm{H}_{2} \mathrm{O}_{2}$ suppress hUSLFs growth.

The balance between ECM protein production and degradation is essential for the onset of POP. The ECM is a major 


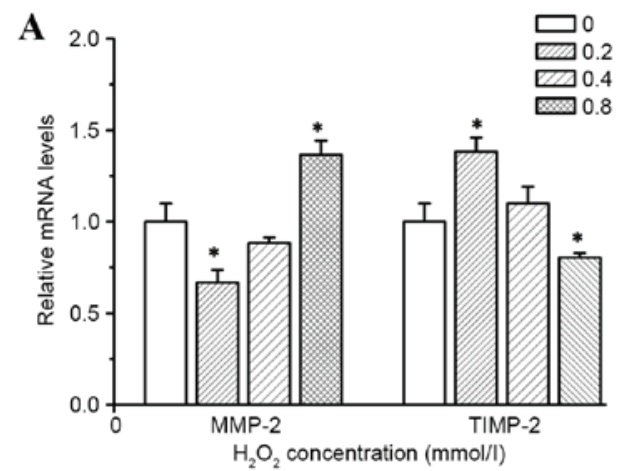

C

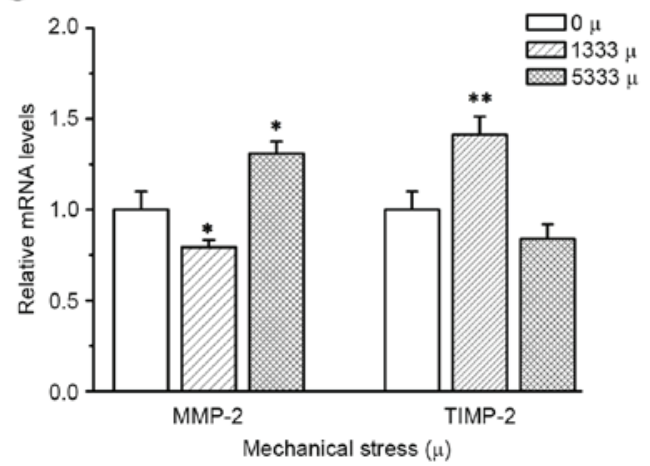

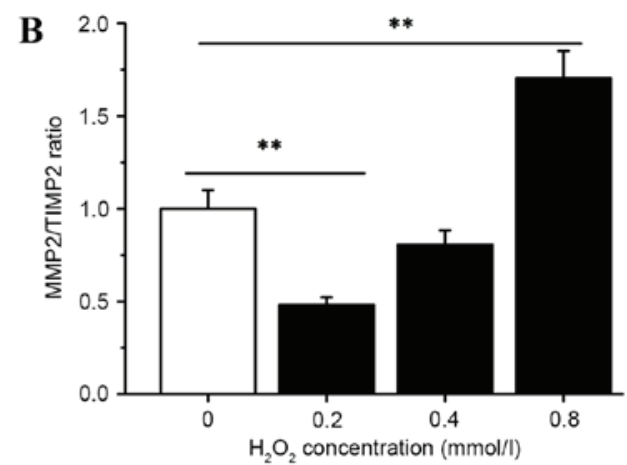

D

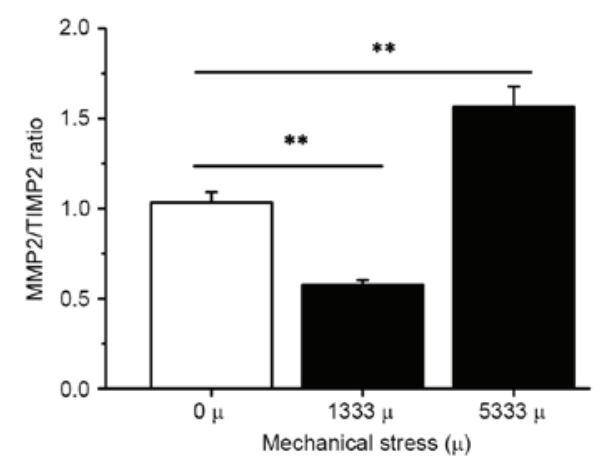

Figure 5. Effects of (A and B) mechanical stress and (C and D) hydrogen peroxide on mRNA expression of MMP-2 and TIMP-2 of hUSLFs. hUSLFs were treated with (A) different concentrations of $\mathrm{H}_{2} \mathrm{O}_{2}$ for $4 \mathrm{~h}$ or $(\mathrm{C})$ mechanical stress. Reverse transcription-quantitative polymerase chain reaction was performed to examine the mRNA expression levels of MMP-2 and TIMP-2. (B and D) Graph depicting the ratio of MMP-2 to TIMP-2 mRNA expression. Error bars represent the mean \pm standard deviation. ${ }^{*} \mathrm{P}<0.05,{ }^{* *} \mathrm{P}<0.01$ vs. $0 \mathrm{mmol} / 1$ (A) or $0 \mu(\mathrm{C})$. hUSLFs, human uterosacral ligament fibroblasts; MMP-2, matrix metalloproteinase-2; TIMP-2, TIMP metallopeptidase inhibitor 2.
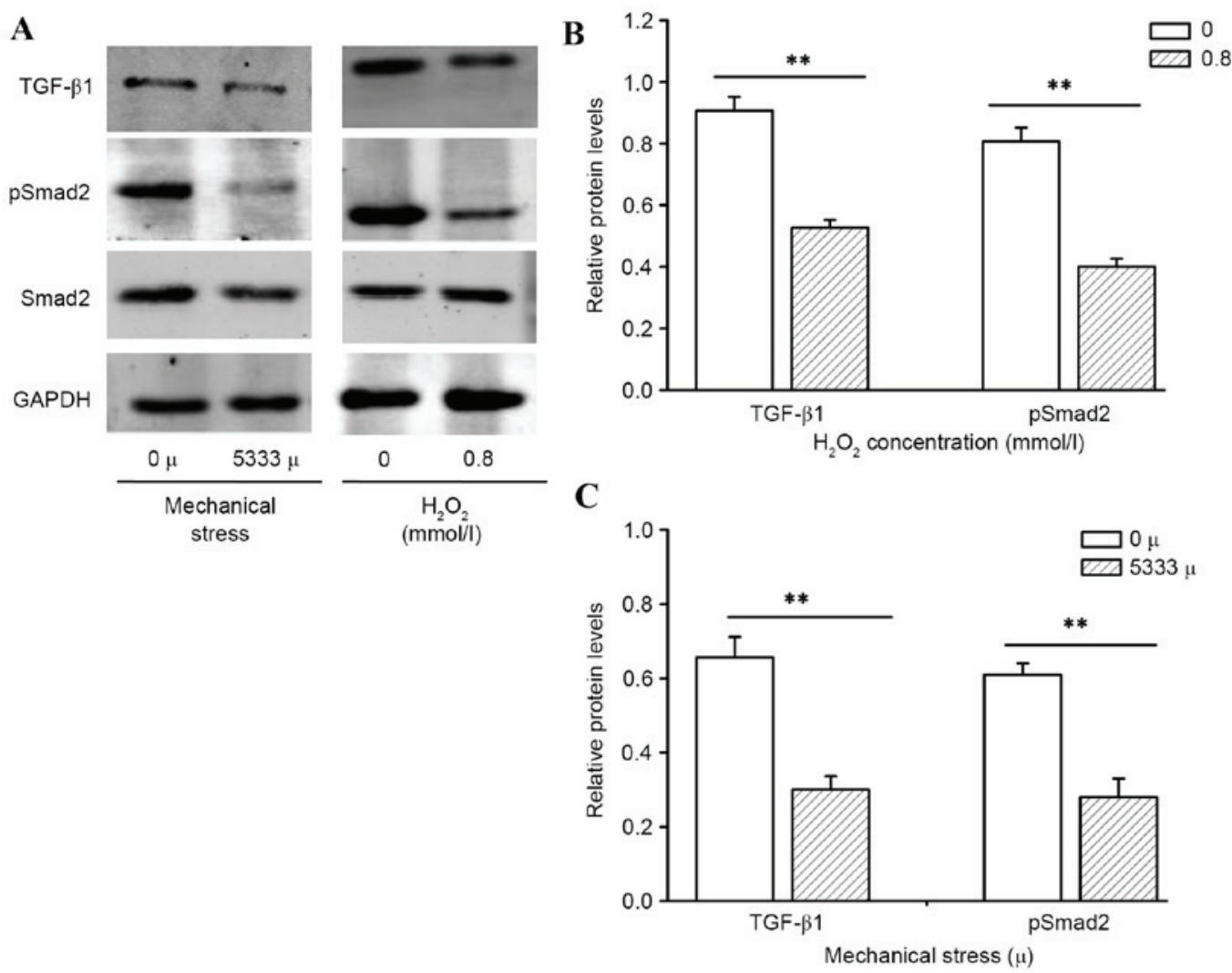

Figure 6. Effect of mechanical stress and hydrogen peroxide on the TGF- $\beta 1 / \mathrm{pSmad} 2$ pathway. (A) Cell lysates were prepared for western blot analysis. GAPDH protein served as the internal control. (B and C) The densitometric intensity of western blot bands were calculated relative to the control groups. Error bars represent the mean \pm standard deviation. ${ }^{*} \mathrm{P}<0.05,{ }^{* *} \mathrm{P}<0.01$. TGF- $\beta 1$, transforming growth factor $\beta 1$; Smad 2 , mothers against decapentaplegic homolog 2 ; p, phosphorylated. 
component of connective tissues, which provide a framework for the pelvic support system. The largest class of fibrous ECM molecules is the collagen family, which includes at least 16 different types of collagen (22). Fibroblasts can synthesize precursors of collagen, including COL1A1 and COL3A1, and elastin, which are secreted into the ECM and assemble into fibrils. Collagen and elastin are the predominant components of connective tissue in uterine ligaments. Type I collagen contributes strength to connective tissues, whereas type III collagen and elastin confer flexibility (23). The ECM is a physical barrier with important structural functions and ECM signaling is received by integrins. Integrin clustering occurs following binding to the ECM, generating intracellular signaling. The present study investigated the change in expression of ECM proteins in hUSLFs upon exposure to mechanical stress and hydrogen peroxide treatment. The present study demonstrated that mechanical stress or hydrogen peroxide could significantly inhibit COL1A1, COL3A1 and elastin expression, however this only occurred when the mechanical stress level reached a certain magnitude and hydrogen peroxide attained a certain concentration. Smaller forces and a lower concentration of $\mathrm{H}_{2} \mathrm{O}_{2}$ could stimulate the ECM protein expression.

Catabolic enzymes, including collagenases or MMPs, cleave the fibrous proteins of the ECM in a process known as catabolism. The ECM is constantly remodeled, and its homeostasis depends on the balance between the synthesis and degradation by MMPs further controlled by activators and inhibitors (TIMPs). MMP-2 is secreted into the extracellular space, and uses elastin, fibronectin and type IV collagen, which are all important components of ECM, as its substrates. TIMP-2 is important in inhibiting MMP-2 deposition and preventing ECM degradation. The present study revealed that the mRNA level of MMP-2 was upregulated and TIMP-2 decreased by overexposure to mechanical force and $\mathrm{H}_{2} \mathrm{O}_{2}$, and additionally the MMP-2/TIMP-2 ratio was increased, which may account for the degradation of the ECM components.

TGF- $\beta 1$ activation enhances fibrogenesis and remodeling of ECM. TGF- $\beta 1 /$ Smad signaling triggers myofibroblasts to synthesize collagen I and collagen III (24). It controls the deposition and turnover of ECM components, including the fibrillar collagens and fibronectin, and regulates the expression of matrix degrading proteolytic enzymes MMPs and their specific tissue inhibitors TIMPs $(25,26)$. TGF- $\beta 1$ initiates its cellular actions by binding to and activating TR $\beta$ II and is mediated by Smad transcription factors. Particular cells were selected to undergo further investigation, based on the ECM component expression levels. The cells were treated with $5,333 \mu$ strain and $0.8 \mathrm{mmol} / 1 \mathrm{H}_{2} \mathrm{O}_{2}$ to investigate the effect on the TGF- $\beta 1$ signaling pathway. The activation of TGF- $\beta 1$ in hUSLFs upon treatment was investigated by western blot analysis. Excessive mechanical force and high concentrations of $\mathrm{H}_{2} \mathrm{O}_{2}$ downregulated the expression levels of TGF- $\beta 1$ and p-Smad2, suggesting that the remodeling of ECM induced by mechanical stress and $\mathrm{H}_{2} \mathrm{O}_{2}$ is associated with the inhibition of the TGF- $\beta 1$ signaling pathway. Previous studies have indicated that the TGF- $\beta 1 /$ Smad signaling pathway is crucial for the activation of a number of fibrillar collagen genes $(27,28)$. The results of the present study indicated that the change of expression of COL1A1, COL $3 \mathrm{~A} 1$ and elastin, which affected
TGF- $\beta 1 /$ Smad signaling, was activated by mechanical stress and $\mathrm{H}_{2} \mathrm{O}_{2}$, in order to trigger ECM deposition or degradation in hUSLFs. Smad2 is the classic downstream signal transducer of TGF- $\beta 1$, which is a major profibrotic factor. The data collectively suggests that the TGF- $\beta 1$ pathway is important in the cellular response to mechanical stress or $\mathrm{H}_{2} \mathrm{O}_{2}$. The Smad signaling pathway is pivotal in signal transduction from the receptors of the TGF- $\beta 1$ superfamily members to the nucleus. However, novel evidence supports the hypothesis that non-Smad signaling pathways also participate in TGF- $\beta 1$ signaling (29). The phosphoinositide-3-kinase/Akt signaling pathway is one of the important non-Smad pathways and is involved in protein synthesis and cell growth (30). In addition to the Smad signaling pathway, TGF- $\beta 1$ may activate the Ras/mitogen activated protein kinase (MAPK) kinase/extracellular-regulated kinase signaling pathway (31). It has been reported that the p38 MAPK signaling pathway is involved in the induction of COL1A1 mRNA by TGF- $\beta 1$ in rat glomerular mesangial cells $(5,32)$.

In conclusion, the results of the present study demonstrated that the disturbance of the balance of MMP/TIMP, via regulation of the TGF- $\beta 1$ signaling pathway, is the major mechanism via which excess mechanical stress or $\mathrm{H}_{2} \mathrm{O}_{2}$ affects the remodeling of ECM.

\section{Acknowledgements}

The present study was supported by the National Natural Science Foundation of China (grant nos. 81270684 and 81471442).

\section{References}

1. Pereira AM, Tudor C, Kanger JS, Subramaniam V and Martin-Blanco E: Integrin-dependent activation of the JNK signaling pathway by mechanical stress. PLoS One 6: e26182, 2011.

2. Furumatsu T, Matsumoto E, Kanazawa T, Fujii M, Lu Z, Kajiki R and Ozaki T: Tensile strain increases expression of CCN2 and COL2A 1 by activating TGF- $\beta$-Smad $2 / 3$ pathway in chondrocytic cells. J Biomech 46: 1508-1515, 2013.

3. Dieter AA, Wilkins MF and Wu JM: Epidemiological trends and future care needs for pelvic floor disorders. Curr Opin Obstet Gynecol 27: 380-384, 2015.

4. Majkusiak W, Horosz E, Tomasik P, Zwierzchowska A, Wielgoś M and Barcz E: Quality of life assessment in women after cervicosacropexy with polypropylene mesh for pelvic organ prolapse: A preliminary study. Prz Menopauzalny 14: 126-129, 2015.

5. Das J, Ghosh J, Manna P and Sil PC: Acetaminophen induced acute liver failure via oxidative stress and JNK activation: Protective role of taurine by the suppression of cytochrome P450 2E1. Free Radic Res 44: 340-355, 2010.

6. Ewies A and Elshafie M: High isoprostane level in cardinal ligament-derived fibroblasts and urine sample of women with uterine prolapse. BJOG 116: 126-128, 2009.

7. Li BS, Hong L, Min J, Wu DB, Hu M and Guo WJ: The expression of glutathione peroxidase- 1 and the anabolism of collagen regulation pathway transforming growth factor-beta1-connective tissue growth factor in women with uterine prolapse and the clinic significance. Clin Exp Obstet Gynecol 40: 586-590, 2013.

8. Kamodyová N, Bañasová L, Janšáková K, Koborová I, Tóthová L', Stanko P and Celec P: Blood contamination in Saliva: Impact on the measurement of Salivary oxidative stress markers. Dis Markers 2015: 479251, 2015.

9. Bujak M and Frangogiannis NG: The role of TGF-beta signaling in myocardial infarction and cardiac remodeling. Cardiovasc Res 74: 184-195, 2007. 
10. Huang XR, Chung AC, Yang F, Yue W, Deng C, Lau CP, Tse HF and Lan HY: Smad3 mediates cardiac inflammation and fibrosis in angiotensin II-induced hypertensive cardiac remodeling. Hypertension 55: 1165-1171, 2010.

11. Froese AR, Shimbori C, Bellaye PS, Inman M, Obex S, Fatima S, Jenkins G, Gauldie J, Ask K and Kolb M: Stretch-induced activation of transforming growth factor- $\beta 1$ in pulmonary fibrosis. Am J Respir Crit Care Med 194: 84-96, 2016.

12. Wells RG: Fibrogenesis. V. TGF-beta signaling pathways. Am J Physiol Gastrointest Liver Physiol 279: G845-G850, 2000.

13. Li FZ, Cai PC, Song LJ, Zhou LL, Zhang Q, Rao SS, Xia Y, Xiang F, Xin JB, Greer PA, et al: Crosstalk between calpain activation and TGF- $\beta 1$ augments collagen-I synthesis in pulmonary fibrosis. Biochim Biophys Acta 1852: 1796-1804, 2015.

14. De Landsheere L, Munaut C, Nusgens B, Maillard C, Rubod C, Nisolle M, Cosson $M$ and Foidart JM: Histology of the vaginal wall in women with pelvic organ prolapse: A literature review. Int Urogynecol J 24: 2011-2020, 2013.

15. Chen B and Yeh J: Alterations in connective tissue metabolism in stress incontinence and prolapse. J Urol 186: 1768-1772, 2011

16. Livak KJ and Schmittgen TD: Analysis of relative gene expression data using real-time quantitative PCR and the 2(-Delta Delta C (T)) Method. Methods 25: 402-408, 2001.

17. Butt RP, Laurent GJ and Bishop JE: Mechanical load and polypeptide growth factors stimulate cardiac fibroblast activity. Ann N Y Acad Sci 752: 387-393, 1995.

18. Kona S, Chellamuthu P, Xu H, Hills SR and Nguyen KT: Effects of cyclic strain and growth factors on vascular smooth muscle cell responses. Open Biomed Eng J 3: 28-38, 2009.

19. Yang G, Crawford RC and Wang JH: Proliferation and collagen production of human patellar tendon fibroblasts in response to cyclic uniaxial stretching in serum-free conditions. J Biomech 37: $1543-1550,2004$.

20. Kaneko D, Sasazaki Y, Kikuchi T, Ono T, Nemoto K, Matsumoto H and Toyama Y: Temporal effects of cyclic stretching on distribution and gene expression of integrin and cytoskeleton by ligament fibroblasts in vitro. Connect Tissue Res 50: 263-269, 2009.

21. Lu M, Gong X, Lu Y, Guo J, Wang C and Pan Y: Molecular cloning and functional characterization of a cell-permeable superoxide dismutase targeted to lung adenocarcinoma cells. Inhibition cell proliferation through the Akt/p27kipl pathway. J Biol Chem 281: $13620-13627,2006$
22. Niu Y, Xie T, Ge K, Lin Y and Lu S: Effects of extracellular matrix glycosylation on proliferation and apoptosis of human dermal fibroblasts via the receptor for advanced glycosylated end products. Am J Dermatopathol 30: 344-351, 2008.

23. Goh JT: Biomechanical and biochemical assessments for pelvic organ prolapse. Curr Opin Obstet Gynecol 15: 391-394, 2003.

24. Gressner AM and Weiskirchen R: Modern pathogenetic concepts of liver fibrosis suggest stellate cells and TGF-beta as major players and therapeutic targets. J Cell Mol Med 10: 76-99, 2006

25. Blavier L, Lazaryev A, Groffen J, Heisterkamp N, DeClerck YA and Kaartinen V: TGF-beta3-induced palatogenesis requires matrix metalloproteinases. Mol Biol Cell 12: 1457-1466, 2001.

26. Schilling TF, Nie Q and Lander AD: Dynamics and precision in retinoic acid morphogen gradients. Curr Opin Genet Dev 22: 562-569, 2012.

27. Verrecchia F, Chu ML and Mauviel A: Identification of novel TGF-beta/Smad gene targets in dermal fibroblasts using a combined cDNA microarray/promoter transactivation approach. J Biol Chem 276: 17058-17062, 2001.

28. Bai G, Yan G, Wang G, Wan P and Zhang R: Anti-hepatic fibrosis effects of a novel turtle shell decoction by inhibiting hepatic stellate cell proliferation and blocking TGF- $\beta 1 / \mathrm{Smad}$ signaling pathway in rats. Oncol Rep 36: 2902-2910, 2016.

29. Moustakas A and Heldin CH: Non-Smad TGF-beta signals. J Cell Sci 118: 3573-3584, 2005.

30. Trager N, Smith A, Wallace Iv G, Azuma M, Inoue J, Beeson C, Haque A and Banik NL: Effects of a novel orally administered calpain inhibitor SNJ-1945 on immunomodulation and neurodegeneration in a murine model of multiple sclerosis. J Neurochem 130: 268-279, 2014.

31. Secker GA, Shortt AJ, Sampson E, Schwarz QP, Schultz GS and Daniels JT: TGFbeta stimulated re-epithelialisation is regulated by CTGF and Ras/MEK/ERK signalling. Exp Cell Res 314: 131-142, 2008

32. Xi L, Xiao C, Bandsma RH, Naples M, Adeli K and Lewis GF: C-reactive protein impairs hepatic insulin sensitivity and insulin signaling in rats: Role of mitogen-activated protein kinases. Hepatology 53: 127-135, 2011. 